\title{
HUBUNGAN KARAKTERISTIK PENYULUH TERHADAP KEBERHASILAN PENGEMBANGAN USAHA PETERNAKAN SAPI POTONG PO DI DI DESA TONDEGESAN, TONDEGESAN SATU DAN TONDEGESAN DUA
}

\author{
Jossy A.M. Lenzun, A. K. Rintjap*, M.Najoan,H. O. Gijoh
}

Fakultas Peternakan Universitas Sam Ratulangi Manado, 95115

\begin{abstract}
ABSTRAK
Penelitian ini bertujuan untuk mempelajari karakteristik penyuluh dari aspek pengetahuan, keterampilan, motivasi, sikap, jarak tempat tinggal dan fasilitas penyuluh di dalam proses keberhasilan usaha pengembangan peternak sapi potong PO di Desa Tondegesan, Desa Tondegesan Satu dan Dua Kecamatan Kawangkoan. Penelitian dirancang sebagai penelitian survei, dengan responden sebanyak 100 peternak. Hasil penelitian menunjukkan: (1) Karakteristik Penyuluh tergolong baikterhadap keberhasilan usaha peternakan sapi potong PO dilihat dari faktor pengetahuan, keterampilan, motivasi, sikap, jarak tempat tinggal dan fasilitas penyuluh, (2) Hal-hal yang relatif sudah baik dari penyuluh dalam perannya sebagai penyuluh adalah materi, sudah berhubungan dengan kebutuhan peternak, dan tingkat kemampuan penyuluh dalam menjelaskan materi.Hasil analisis menunjukkan bahwa nilai $\mathrm{x}^{2}$ hitung $=$ 26,586, yaitu lebih besar darinilai $\mathrm{x}^{2}$ tabel yaitu $\quad 9,488$. Dapat disimpulkan bahwa ada kaitan yang signifikan antara karakteristik penyuluh dengan keberhasilan pengembangan usaha ternak sapi potong PO.

Kata kunci: Karakteristik penyuluh, Keberhasilan
\end{abstract}

Korespondensi (correspoding author) Email :anneke_rintjap@yahoo.com
ABSTRACT

RELATIONSHIP OF $r$ THE
AUTHOR CHARACTERISTICS
WITH THE SUCCESS OF
DEVELOPMENT OF
LIVESTOCK COW
TONDEGESAN, TONDEGESAN
ONE, AND TONDEGESAN TWO

VILLAGE. Theaim of this studi was to evaluate the characteristics of extension agents from the aspects of knowledge, skills, motivation, attitude, distance of residence and extension facilities in developing PO cattle breeders in Tondegesan Village, Tondegesan Village One and Two Kawangkoan District. The study was designed as a survey to 100 farmers as respondents. The results of the study showed (1) Characteristics of Extension Workers classified as good for developing of $\mathrm{PO}$ beef cattle business indicated from knowledge, skills, motivation, attitude of farmers, distance of residence and extension facilities, (2) Relatively good things from extension agents in their roles as an instructor isprovided material extension considered on farmers needed, and the ability of the instructor in explaining the material. The results of the analysis show that the value of $x^{2}$ count $=26.586$, which is greater than the value of $x^{2}$ table which is 9,488 . Thus, we conclude that there is a significant correlation between the characteristics of extension agents and the successful 
development of PO beef cattle business.

Keywords: Characteristics, extension agents, success

\section{PENDAHULUAN}

Penyuluh adalah orang yang memiliki peran, tugas atau profesi dalam memberikan pendidikan, bimbingan dan penerangan kepada masyarakat untuk mengatasi berbagai masalah, seperti pertanian dan kesehatan, sehingga dapat mencapai sasaran yang telah ditetapkan. Penyuluh juga dikenal dengan sebutan juru penerang. Biasanya penyuluh atau juru penerang menjalankan perannya dengan cara mengadakan ceramah, wawancara, dan diskusi bersama khalayak khusus. Pemegang peran serupa ini, dalam bahasa Inggris disebut counsellor, yang artinya penasihat. Pemegang peran seperti ini dalam beberapa bidang kegiatan di Indonesia mempunyai sebutan yang berbeda-beda. Umpamanya, juru penerang masalah pertanian disebut Petugas Penyuluh Lapangan (PPL), dengan tugas mengusahakan perubahan dalam pola pikir dan perilaku petani agar dapat mencapai produksi pertanian yang lebih tinggi. Para petani didorong untuk menggunakan cara-cara yang efektif dan efisien dengan mempraktekkan apa yang disebut Panca Usaha Tani sehingga kesejahteraan mereka diharapkan dapat meningkat (Mardikanto, 2009).

Menurut Jahi (2006), mengatakan bahwa pelayanan kegiatan penyuluhan merupakan salah satu usaha untuk meningkatkan kemampuan peternak dan menunjang perbaikan usaha ternak melalui upayanya untuk mengubah perilaku peternak ke arah usaha beternak yang lebih baik (better farming), berusaha ternak lebih baik (better business), kesejahteraan hidup yang lebih baik (better living), dapat menjaga lingkungan hidup dengan lebih baik (better environtment), mencapai kehidupan masyarakat yang lebih baik (better community). Kondisi tersebut dapat dicapai apabila penyuluh peternakan difasilitasi oleh pengurus koperasi untuk mengidentifikasi kebutuhan peternak, melakukan percontohan, mendorong kerja sama diantara peternak, mendorong minat peternak untuk memanfaatkan sumberdaya alam dan sumberdaya manusia (tenaga kerja) secara optimal. (Hernanda 2015).

Berdasarkan pengamatan sementara peneliti, ada beberapa gejala yang membutuhkan penanganan 
mengenai karakteristik penyuluh peternakanterhadap keberhasilan pengembangan usaha peternakan sapi di Desa Tondegesan, Tondegesan Satu dan Tondegesan Dua. Identifikasi yang perlu diperhatikan antara lain :

1. Keterbatasan tenaga penyuluh peternak sapi di Kecamatan Kawangkoan mengakibatkan informasi yang disampaikan oleh tenaga penyuluh kepada peternak sapi tidak terealisasi secara rutin.

2. Hal-hal yang dianggap masih belum dilakukan dengan baik oleh penyuluh dalam perannya sebagai pendidik adalah dalam: kelengkapan materi aspek manajemen usaha, perhatiannya terhadap kesiapan mental peternak, dan pengulangan aktivitas demonstrasi.

Dalam pelaksanaan usaha peternak sapidi daerah ini mengalami berbagai permasalahan, di antaranya: (a) sistem pemeliharaan sapi kebanyakan masih secara tradisional; (b) kurangnya pemanfaatan inseminasi buatan (IB); (c) kurangnya pemanfaatan lahan untuk ditanamai hijauan makanan ternak, sehingga terkendala dalam penyediaan pakan; (d) lokasi budidaya yang terpencil dengan skala pemilikan ternak yang tergolong rendah; dan (e) peternak sapi belum menguasai caracara pemasaran yang baik.

Belum berhasilnya pembangunan pada sub-sektor peternakansapi, selain dipengaruhi oleh permasalahan tersebut, diduga diakibatkan oleh karakteristikpenyuluh yang masih tergolong rendah. (Elly. 2008).

Dalam penelitian karakteristik penyuluh ditentukan oleh beberapa faktor antara lain pengetahuan, keterampilan, motivatsi, sikap, jarak tempat tiggal dan fasilitas penyuluh. (Charina, 2015).

Rumusan Masalah

Berdasarkan uraian masalah tersebut, maka yang menjadi masalah dalam penelitian ini adalah: Bagaimana Hubungan Karakteristik Penyuluh Terhadap KeberhasilanPengembangan Usaha Peternakan SapiPotong PO di Di Desa Tondegesan, Tondegesan Satu dan Tondegesan Dua?

Tujuan Penelitian

Tujuan Penelitian ini adalah untuk mendeskripsikanhubungan karakteristik penyuluh yang terdiri dari aspek seperti pengetahuan, keterampilan, motivasi, sikap, jarak tempat tinggal, fasilitas penyuluh terhadap keberhasilan pengembangan 
usaha peternakan sapi potong PO di desa Tondegesan, Tondegesan Satu dan desa Tondegesan Dua.

Hipotesis

H0: tidak ada kaitan antara karakteristik penyuluh dengan keberhasilan pengembangan usaha ternak sapi potong PO HA: ada kaitan antara karakteristik penyuluh dengan keberhasilan pengembangan usaha ternak sapi potong PO

\section{METODE PENELITIAN}

Penelitian ini dilakukan di Desa Tondegesan, Desa Tondegesan Satu dan Desa Tondegesan DuaKecamatan Kawangkoan (studi Kasus) dari tanggal 1 September sampai dengan 30 November 2017

Jenis dan Sumber Data

Jenis data yang digunakan penulis dalam penelitian ini adalah sebagai berikut:

a. Data Primer

b. Data Sekunder

Pengumpulan data dilakukan dengan beberapa metode yaitu :

1. Wawancara langsung

2. Observasi

3. Dokumentasi

Data primer diperoleh dengan teknik wawancara mendalam dan diskusi secara langsung yang didukung oleh sejumlah instrument/alat yaitu: kuisioner dan alat dokumentasi seperti kamera foto.

Data mengenai variabel pengetahuan, keterampilan, motivasi, Sikap, jarak tempat tinggal, fasilitas penyuluh dan keberhasilan peternakdiukur dengan menerapkan "Skala Likert", dengan membentuk lima kategori jawaban dari pertanyaan yang diajukan. Skor dinyatakan dalam bilangan bulat $(1,2,3,4,5)$. Untuk pertanyaan positif respon sangat setuju diberikan skor 5, sebaliknya sangat tidak setuju diberikan skor 1, sedangkan untuk pertanyaan negatif respon sangat tidak setuju diberi skor 5, sebaliknya sangat setuju diberi skor 1. (Singarimbun dan Effendi,1989).

Perolehan total skor variabel pengetahuan, keterampilan, motivasi, sikap, jarak tempat tinggal, fasilitas dan keberhasilan peternak dalam usaha sapi disajikan dalam bentuk persen (\%) berdasarkan jumlah skor maksimum ideal (Riduwan.2013).

Mengacu pada hasil kuesioner pada lampiran 1 bahwa didapatkan untuk konstruk kinerja dengan skor tertinggi $100 \quad(100 \%)$ dan skor terendah $20 \quad(20 \%)$, variabel pengetahuan skor tertinggi 30 (100\%) 
dan skor terendah 6 (20\%), variabel keterampilan skor tertinggi $30(100 \%)$ dan skor terendah 6 (20\%), variabel motivasi skor tertinggi $45(100 \%)$ dan skor terendah 9 (20\%), dan variabel sikap skor tertinggi $45(100 \%)$ dan skor terendah 9 (20\%). Variabel jarak tempat tinggal skor tertinggi 15 (100\%) dan skor terendah 3 (20\%), serta variabel fasilitas skor tertinggi 15 (100\%) dan skor terendah $3(20 \%)$. Untuk variabel keberhasilan skor tertinggi $70(100 \%)$ dan skor terendah $14(20 \%)$.

Untuk mengetahui nilai-nilai pengetahuan, keterampilan, motivasi, sikap, jarak tempat tinggal, fasilitas penyuluh pertanian, dan keberhasilan peternak, masing-masing kategori dapat dilihat dari persentase pencapaian skornya dengan menggunakan rumus Interval Kelas yang dikemukakan oleh Riduwan dan $\operatorname{Akdon}(2010)$.

Hubungan antara karakteristik penyuluh yang meliputi pengetahuan, keterampilan, motivasi, sikap, jarak tempat tinggal, dan fasilitas dengan keberhasilan pengembangan usaha peternakan sapi masing-masing diuji dengan menggunakan uji Kai Quadrat(Pearson Chi Square Test).

\section{HASIL DAN PEMBAHASAN}

Berdasarkan penelitian yang telah dilakukan, bahwa pemeliharaan ternak sapi potong PO di desa Tondegesan, Desa Tondegesan Satu dan Desa Tondegesan DuaKecamatan Kawangkoan merupakan usaha skala rumah tangga atau usaha sampingan, dilihat dari jumlah kepemilikan ternak terbanyak yaitu berada pada kisaran 1-10 ekor ternak oleh 100 orang responden.

Variabel-variabel yang
diamati dalam penelitian ini
menunjukkan hubungan antara
pengembangan usaha peternakan
sapi potong dengan pengetahuan,
keterampilan, motivasi, sikap, jarak
tempat tinggaldan fasilitas
penyuluh.

Berdasarkan hasil perhitungan yang dilakukan dengan menggunakan analisis Chi Square, maka di ketahui bahwa variable pengetahuan, keterampilan, motivasi, sikap, jarak tempat tinggaldan fasilitas penyuluh mempunyai korelasi secara bersamasama terhadap keberhasilan pengembangan usaha peternakan sapi potong PO di Desa Tondegesan, Desa Tondegesan Satu dan Desa Tondegesan Dua. 
Tabel 1 Pengetahuan Penyuluh Terhadap Keberhasilan Pengembangan Usaha Peternakan Sapi Potong PO

\begin{tabular}{|c|c|}
\hline \multirow[t]{2}{*}{ No Pengetahuan } & Jumlah Responden(Peternak) \\
\hline & Orang $\%$ \\
\hline Sangat Tinggi & 66 \\
\hline Tinggi & 34 \\
\hline Sedang & - \\
\hline Rendah & - \\
\hline Sangat Rendah & - \\
\hline Jumlah & 100 \\
\hline Dari tabel $1 \mathrm{di}$ atas dapat & \multirow{5}{*}{$\begin{array}{l}\text { penerangan yang keliru. Selanjutnya } \\
\text { pengetahuanberbeda dengan buah } \\
\text { pikiran, karena tidak semua buah } \\
\text { pikiran } \\
\text { mengetahuan.(Asngari, 2008). }\end{array}$} \\
\hline dijelaskan bahwa sebanyak66orang & \\
\hline$(66 \%)$ menyatakan & \\
\hline penyuluh & \\
\hline pengetahuan termasuk dalam & \\
\hline kategori "sangat tinggi", sedangkan & \multirow{7}{*}{$\begin{array}{l}\text { Pada tabel } 3 \text { di bawah ini } \\
\text { sebagian besar responden yaitu } 86 \\
\text { orang }(86 \%) \text { menyatakan bahwa } \\
\text { penyuluh memiliki keterampilan } \\
\text { dalam kategori "sangat terampil" } \\
\text { sedangkan sisanya yaitu } 14 \text { orang } \\
\text { responden }(14 \%) \text { menyatakan bahwa }\end{array}$} \\
\hline sisanya yaitu 34 orang responden & \\
\hline (34\%) menyatakan bahwa penyuluh & \\
\hline memiliki pengetahuan dalam & \\
\hline "tinggi" terhadap & \\
\hline keberhasilan pengembangan usaha & \\
\hline peternakan sapi potong PO. Rataan & \\
\hline persentase pencapaian skor & penyuluh memiliki keterampilan \\
\hline pengetahuan penyuluh mengenai & dalam kategori "terampil" terhadap \\
\hline keberhasilan pengembangan usaha & keberhasilan pengembangan usaha \\
\hline peternakan sapi potong PO adalah & peternakan sapi potong PO. Hal ini \\
\hline 26,06 atau $86,86 \%$ dari skor & menunjukkan bahwa \\
\hline maksimal ideal 30. Menurut Dali & mampu menerapkan pengetahuan \\
\hline (2017), pengetahuan adalah kesan & yang dimilikinya kedalam bentuk \\
\hline dalam pikiran manusia sebagai hasil & kegiatan penyuluhan \\
\hline proses panca indera, & pengembangan usaha sapi. \\
\hline
\end{tabular}

dengan kepercayaan, takhyul dan 
Tabel 2 Keterampilan Penyuluh Terhadap Keberhasilan Pengembangan Usaha Peternakan Sapi Potong PO

\begin{tabular}{llll}
\hline \multirow{2}{*}{ No } & Keterampilan & \multicolumn{2}{c}{ Jumlah Responden(Peternak) } \\
\cline { 3 - 4 } & & Orang & $\%$ \\
\hline 1 & Sangat Terampil & 86 & 86 \\
2 & Terampil & 14 & - \\
3 & Sedang & - & - \\
4 & Rendah & - & - \\
5 & Sangat Rendah & - & 100 \\
\hline
\end{tabular}

Keterampilan adalah kemampuan seseorang menerapkan pengetahuan kedalam bentuk tindakan. Hafsah (2009)mengatakan, keterampilan adalah kecakapan yang berhubungan dengan tugas yang dimiliki dan dipergunakan oleh seseorang pada waktu yang tepat.Pada tabel 3 di bawah ini dapat dijelaskan bahwa sebagian besar responden yaitu 75 orang (75 \%) menyatakan bahwa penyuluh memiliki motivasi dalam kategori "sangat kuat" sedangkan sisanya yaitu 25 orang responden (25\%) menyatakan bahwa penyuluh memiliki motivasi dalam kategori

Tabel 3 Motivasi Penyuluh Terhadap Keberhasilan Pengembangan Usaha Peternakan Sapi Potong PO.

\begin{tabular}{llll}
\hline No & Motivasi & \multicolumn{2}{c}{ Jumlah Responden(Peternak) } \\
\cline { 3 - 4 } & & Orang & $\%$ \\
\hline 1 & Sangat Kuat & 75 & 75 \\
3 & Kuat & 25 & 25 \\
4 & Sedang & - & - \\
5 & Lemah & - & - \\
\hline \multicolumn{2}{l}{ Jumlah Jumlah } & - & - \\
\hline
\end{tabular}


Tabel 4 Sikap Penyuluh Terhadap Keberhasilan Pengembangan Usaha Peternakan Sapi Potong PO

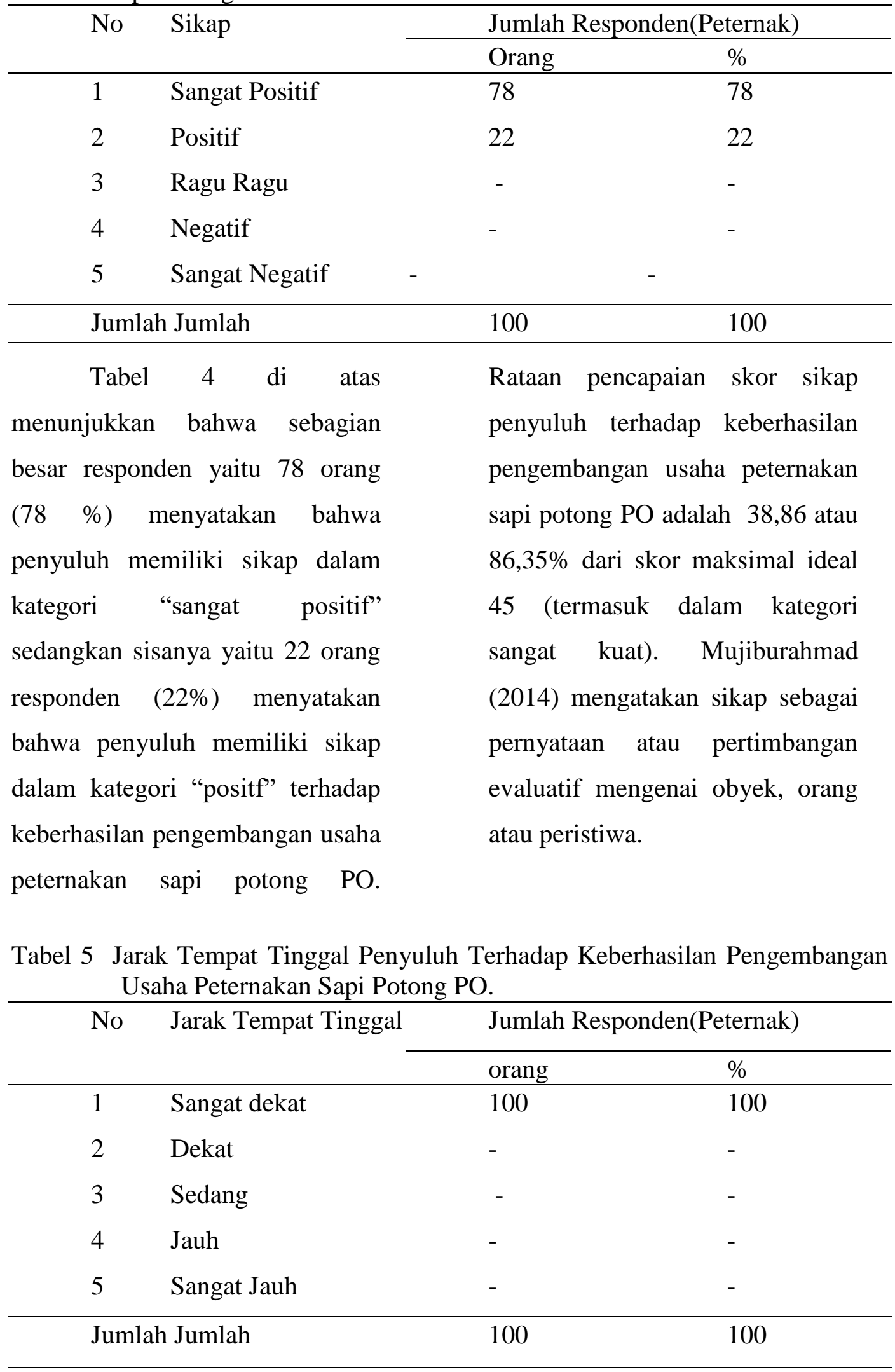


Terlihat pada tabel 5 di atas penyuluhmemiliki jarak tempat tinggal termasuk dalamkategori "sangat dekat" (1-10 km).Dengan sangat dekatnya jarak tempat tinggal penyuluh pertanian dengan peternak sapi binaannya akan mampu memberikan kemudahan bagi penyuluh dalam menjalankan tugasnya sebagai penyuluh. Dengan sangat dekatnya jarak tempat tinggal penyuluh dengan peternak binaannya akan mampu memberikan kemudahan bagi penyuluh dalam menjalankan tugasnya. Jarak adalah jauh antara dua benda atau tempat, sedangkan tempat tinggal adalah rumah yang didiami (ditinggali) atau ditempati.

Dari gambaran tabel 6 di bawah ini seluruh responden menyatakan bahwa penyuluh memiliki fasilitas yang kurang lengkap terhadap keberhasilan pengembangan usaha peternakan sapi potong PO. Rataan pencapaian skor fasilitas dalam pengembangan usaha peternakan sapi potong PO adalah 9 atau $60 \%$ dari skor maksimal 15 (termasuk kategori kurang lengkap

Hal ini menunjukkan bahwa fasilitas penyuluh masih kurang lengkap, tentu akan mempengaruhi kinerja mereka. Fasilitas yang memadai mampu menciptakan produktivitas kerja yang efisien. Oleh karena itu, dituntut kesiapan dan kesanggupan dari manusia itu sendiri dalam mengoperasikan fasilitas atau peralatan kerja tersebut. (Asngari, 2008).

Tabel 6. Fasilitas Penyuluh Terhadap Keberhasilan Pengembangan Usaha Peternakan Sapi Potong PO.

\begin{tabular}{|c|c|c|c|}
\hline \multirow[t]{2}{*}{ No } & \multirow[t]{2}{*}{ Fasilitas } & \multicolumn{2}{|c|}{ Jumlah Responden(Peternak) } \\
\hline & & orang & $\%$ \\
\hline 1 & Sangat Lengkap & - & - \\
\hline 2 & Lengkap & - & - \\
\hline 3 & Kurang Lengkap & 100 & 100 \\
\hline 4 & Sangat Kurang Lengkap & - & - \\
\hline 5 & Sangat Tidak Tersedia & - & - \\
\hline \multicolumn{2}{|c|}{ Jumlah Jumlah } & & 100 \\
\hline
\end{tabular}


Tabel 7. Tabel Kontingensi Hasil Uji Chi Square Faktor-faktor Karakteristik Penyuluh Terhadap Kebehasilan Pengembangan Usaha Peternak Sapi Potong PO

\begin{tabular}{lrrr}
\hline Kategori & Berhasil & Tidak Berhasil & Total \\
\hline Pengetahuan & 4 & 2 & 6 \\
O & 4,14 & 1,86 & \\
E & & & \\
Keterampilan & 16 & 15 & 31 \\
O & 21,39 & 9,61 & \\
E & & & \\
Motivasi & 14 & 11 & 25 \\
O & 17,25 & 7,75 & \\
E & & & \\
Sikap & 19 & 1 & 20 \\
O & 13,8 & 6,2 & 18 \\
E & & & \\
Jarak Tempat Tinggal & 16 & 2 & \\
O & 12,42 & 5,58 & \\
E & 69 & 31 & \\
\hline Total & & & \\
\hline
\end{tabular}

Hasil perhitungan pada tabel 7

$\mathrm{x}^{2}$ hitung $=26,586$

$\mathrm{x}^{2}$ tabel $=9,488$.

Hasil analisis menunjukkan bahwa nilai $\mathrm{x}^{2}$ hitung $=26,586$, lebih besar darinilai $\mathrm{x}^{2}$ tabel yaitu 9,488 . Dengan demikian, kita simpulkan bahwa ada kaitan yang signifikan antara karakteristik penyuluh dengan keberhasilan pengembangan usaha ternak sapi potong PO.

Nilai O (Observasi) adalah nilai pengamatan di lapangan Nilai E (expected) adalah nilai yang diharapkan, dihitung sbb:
1. Nilai E untuk kategori PengetahuanBerhasil $=(6 \mathrm{x}$ 69) $/ 100=4,14$

2. Nilai $E$ untuk kategori Pengetahuan Tidak Berhasil $=(6$ x 31$) / 100=1,86$

3. Nilai E untuk kategori KeterampilanBerhasil $=(31 \mathrm{x}$ 69) $/ 100=21,39$

4. Nilai E untuk kategori Keterampilan Tidak Berhasil = $(31 \times 31) / 100=9,61$

5. Nilai E untuk kategori MotivasiBerhasil $=(25 \times 69) / 100$ $=17,25$ 
6. Nilai E untuk kategori Motivasi Tidak Berhasil $=(25 \times 31) / 100=$ 7,75

7. Nilai E untuk kategori SikapBerhasil $=(20 \times 69) / 100=$ 13,8

8. Nilai E untuk kategori Sikap Tidak Berhasil $=(20 \times 31) / 100=$ 6,2

9. Nilai E untuk kategori Jarak Tempat TinggalBerhasil $=(18 \mathrm{x}$ $69) / 100=12,42$

10.Nilai E untuk kategori Jarak Tempat TinggalTidak Berhasil = $(24 \times 82) / 130=5,58$

\section{KESIMPULAN DAN SARAN}

Karakteristik penyuluh terhadap keberhasilan pengembangan usaha peternak sapi potong PO di desa Tondegesan, Tondegesan Satu dan Tondegesan Dua termasuk dalam kategori baik. Ada kaitan yang signifikan antara karakteristik penyuluh dengan keberhasilan pengembangan

Mengingat peran penyuluh sangat penting dalam pengembangan usaha peternakan sapi potong PO, maka diperlukan sifat bertanggungjawab, inovatif, dan keteladanan yang tinggi. Selain itu diperlukan juga teknik penyuluhan yang lebih baik juga sehingga dapat meningkatkan keberhasilan peternak dalam usaha peternakan sapi potong PO. Perlu penelitian lanjutan mengenai Peran Penyuluh dalam Pengembangan Usaha Peternakan Sapi Potong PO di Kabupaten Minahasa dari aspek sinergitas peran penyuluh, peternak danpemerintah.

\section{DAFTAR PUSTAKA}

Asngari, P. S. 2008. Faktor-faktor penentu peningkatan kinerja penyuluhan pertanian dalam memberdayakan petani (kasus di kabupaten kampar provinsi riau). Jurnal Komunikasi Pembangunan. 4 (2): 102 108.

Charina, A. 2015. Kajian kinerja penyuluh pertanian di kecamatan sindangkasih, kabupaten ciamis, jawa barat. Jurnal Social Economic of Agriculture 4 (1):203 - 209

Dali, I. 2017. Hubungan kinerja penyuluh pertanian lapangan dengan keberhasilan peternak sapi potong di kecamatan kwandang kabupaten gorontalo utara. Jurnal zootek 37 (2): 403-414

Elly. F. H. 2008. Ternak sapi dan prospekpengembangannya di kabupatenminahasa. Jurnal Zootek 29.: 249-259 
Hafsah, M J. 2009. Penyuluhan Peternak sapi di Era Otonomi daerah. Jakarta: PT Pustaka Sinar Harapan

Hernanda T.A, 2015. Tingkat kinerja penyuluh pertanian di Kabupaten Ogan Komering Ulu (oku) Selatan. Jurnal Penyuluhan 11 (1): 349-359

Jahi. 2006. Kinerja penyuluh pertanian di beberapa Kabupaten, Provinsi Jawa Barat.. Jurnal Penyuluhan. 2 (2): 321-331

Mardikanto. 2009. Sistem Penyuluhan Pertanian. Surakarta: Lembaga Pengembangan Pendidikan (LPP) UNS dan UPT Penerbitan dan Pencetakan UNS (UNS Press).
Mujiburahmad M. 2014. Kinerja penyuluh pertanian di kabupaten pidie propinsi aceh dalam melaksanakan tugas dan fungsi. Jurnal Penyuluhan10 (2):: 456-466

Ruhimat, I. S.2015. Tingkat motivasi petani dalam penerapan sistem agroforestry. Jurnal Penelitian Sosial dan Ekonomi Kehutanan 12 (2) : 1-5

Riduwan.2013.Skala Pengukuran Vaiabel - Variabel Penelitian. Bandung: Alfabeta

Riduwan dan Akdon. 2010. Rumus dan Data Dalam Analisis Statistika. Bandung:Alfabeta 